\title{
Effects of nurse-perceived authentic leadership and organizational culture on job attitude: focused on the mediating effects of psychological capital and leader- member exchange.
}

\author{
Sang Sook Han ${ }^{1}$, Hee Young Woo ${ }^{2 *}$ \\ ${ }^{1}$ Department of Nursing, Kyung Hee University, 26, Kyungheedae-ro, Dongdaemun-gu, Seoul, Republic of Korea \\ ${ }^{2}$ Department of Nursing, Sahmyook Health University, 82 Manguro, Dongdaemun-gu Seoul, Republic of Korea
}

\begin{abstract}
This study aimed to investigate the effects of authentic leadership and organizational culture, perceived by nurses working at medical institutions, on work meaning and work engagement, which are job attitudes, through the mediators, leader-member exchange and psychological capital, in 301 nurses working at three general hospitals with over 300 beds. The analysis results showed that authentic leadership perceived by nurses had a direct effect on enhancing leader-member exchange $(\beta=0.95$, $p=0.004)$, and organizational culture had a direct effect on increasing psychological capital $(\beta=0.56$, $p=0.004)$. Organizational culture had an indirect effect on increasing work meaning $(\beta=0.32, p=0.004)$, and psychological capital had a direct effect on increasing work meaning $(\beta=0.56, p=0.004)$. Work meaning had a direct effect on enhancing work engagement $(\beta=0.89, p=0.004)$, and organizational culture had an indirect effect on enhancing work engagement $(\beta=0.41, p=0.004)$. In addition, psychological capital had a direct effect $(\beta=0.62, p=0.004)$ and an indirect effect $(\beta=0.33, p=0.004)$ on enhancing work engagement. Therefore, it is necessary to develop human resource management programs that consider authentic leadership of the leader and organizational culture, and mediating effects of leader-member exchange and psychological capital in order to improve job attitudes of nurses.
\end{abstract}

Keywords: Authentic leadership, Engagement, LMX, Meaning, Psychological capital.

\section{Introduction}

Recently, changes in the healthcare environment have been gradually accelerating in Korea, and there is an urgent need for strategies to cope with these changes [1]. In particular, the importance of positive job attitudes of nurses who occupy the largest number of personnel in hospitals is emphasized [2]. In recent years, it has been reported in the nursing organization that if work meaning is enhanced, which is a positive job attitude, the quality of nursing is improved, as well as hospital achievement, as work engagement increases [3]. Studies have been conducted focusing on psychological capital, which is an emotional state that members have already been accumulating, and leader-member exchange (LMX) in the organization as mediators that may influence positive job attitudes [4]. Moreover, Henderson et al. suggested that multiple levels of precedence factors could make an influence in this psychological process. Organizational culture and leadership at the organizational level are not only interacting with each other, but are also key factors affecting the psychological processes of the members [5]. Recently, Korean nursing academia has paid attention to authentic leadership [6]. Authentic leadership is a leadership where the leader treats individuals with authenticity, and has a characteristic of interacting with their members individually. Understanding and mediating the organizational culture of nurses, which constitutes a significant part of the hospital organization, has become an essential management strategy for effectively operating the hospital organization [6,7]. Previous studies on the factors identified before include the studies on the effects of authentic leadership and organizational culture on psychological capital and leader-member exchange (LMX) $[4,8,9]$ and studies on the effects of psychological capital and leader-member exchange (LMX) on work meaning and work engagement, which are job attitudes $[3,5,10]$. However, most of the studies were conducted mainly on employees of companies and service organizations, and no empirical studies have been conducted on nurses. Therefore, this study aimed to investigate the effects of authentic leadership of the boss and organizational culture, perceived by nurses, on work meaning and work engagement, which are job attitudes, through the mediators, psychological capital and leader-member exchange (LMX) in clinical nurses and to provide fundamental data to promote the job attitudes of clinical nurses directly related to the public health. 


\section{Materials and Methods}

This study is a path analysis study that establishes a hypothetical model on authentic leadership of the boss perceived by nurses, organizational culture, leader-member exchange, psychological capital, work meaning, and work engagement and verifies the model fit and hypotheses. The subjects were 301 nurses working at general hospitals with over 300 beds. Authentic leadership, organizational culture, psychological capital, leader-member exchange, work meaning, and work engagement were measured by using the Authentic Leadership Questionnaire [11], Organizational Culture Questionnaire [12], Leader Member Exchange scale [13], Psychological capital Questionnaire: PCQ [14], The Work and Meaning Inventory: WAMI [15], and Utrecht Work Engagement Scale: UWES-9 [16]. SPSS Windows 20.0 was used to analyse demographic characteristics of subjects and validity and reliability of study tools. AMOS 20.0 was used to verify the validity of the factors for constructing the structural equation model for nurses' job attitudes.

\section{Results}

As a result of verifying path coefficients, authentic leadership perceived by nurses had a positive effect on leader-member exchange $(\beta=0.09, \mathrm{p}<0.004)$, and organizational culture on psychological capital $(\beta=0.56, \mathrm{p}<0.004)$. Psychological capital $(\beta=0.56, \quad p<0.004)$ and leader-member exchange $(\beta=0.19$, $\mathrm{p}<0.008$ ) had positive effects on work meaning. Psychological capital $(\beta=0.41, p<0.004)$ and work meaning $(\beta=0.56$, $\mathrm{p}<0.004)$ had positive effects on work engagement. Among 10 hypotheses, 6 hypotheses were selected, the fit indices of the study model were $\chi^{2}=447.81 \quad(\mathrm{df}=2, \mathrm{p}=0.680), \chi^{2} / \mathrm{df}=2.27$, $\mathrm{GFI}=0.88, \mathrm{AGFI}=0.85, \mathrm{RMRS}=0.03, \mathrm{NFI}=0.90, \mathrm{CFI}=0.94$, and $\mathrm{RMSEA}=0.07$. Organizational culture perceived by nurses had a direct effect on increasing psychological capital $(\beta=0.56$, $\mathrm{p}=0.004$ ), and authentic leadership had a direct effect on enhancing leader-member exchange $(\beta=0.95, \quad p=0.004)$. Organizational culture had an indirect effect on increasing work meaning $(\beta=0.32, p=0.004)$, and psychological capital had a direct effect on increasing work meaning $(\beta=0.56$, $\mathrm{p}=0.004)$. Work meaning had a direct effect on enhancing work engagement $(\beta=0.89, p=0.004)$, and organizational culture had an indirect effect on enhancing work engagement $(\beta=0.41$, $\mathrm{p}=0.004)$. In addition, psychological capital had a direct effect $(\beta=0.62, p=0.004)$ and an indirect effect $(\beta=0.33, p=0.004)$ on enhancing work engagement (Table 1).

Table 1. Standardized direct, indirect, total effect for the hypothetical model.

\begin{tabular}{|c|c|c|c|c|}
\hline Exogenous variables & Endogenous variables & Direct effects (p) & Indirect effects (p) & Total effects (p) \\
\hline Authentic leadership & Psychological capital & $-0.01(0.919)$ & & $-0.01(0.919)$ \\
\hline Organizational culture & & $0.56(0.004)$ & & $0.56(0.004)$ \\
\hline Authentic leadership & Leader-member exchange & $0.95(0.004)$ & & $0.95(0.004)$ \\
\hline Organizational culture & & $-0.15(0.282)$ & & $-0.15(0.282)$ \\
\hline Psychological capital & & $0.04(0.445)$ & & $0.04(0.445)$ \\
\hline Authentic leadership & Work meaning & & $0.18(0.030)$ & $0.18(0.030)$ \\
\hline Organizational culture & & & $0.32(0.004)$ & $0.32(0.004)$ \\
\hline Psychological capital & & $0.56(0.004)$ & & $0.56(0.004)$ \\
\hline LMX & & $0.19(0.008)$ & & $0.19(0.008)$ \\
\hline Authentic leadership & Work engagement & & $0.11(0.241)$ & $0.11(0.241)$ \\
\hline Organizational culture & & & $0.41(0.004)$ & $0.41(0.004)$ \\
\hline Psychological capital & & $0.62(0.004)$ & $0.33(0.004)$ & $0.95(0.004)$ \\
\hline LMX & & $0.01(0.796)$ & $0.11(0.008)$ & $0.12(0.045)$ \\
\hline Work meaning & & $0.89(0.004)$ & & $0.89(0.004)$ \\
\hline
\end{tabular}

\section{Discussion}

Organizational culture perceived by nurses had a direct effect on increasing psychological capital, which is consistent with the study result on service workers [17], suggesting that positive organizational culture perceived by nurses can increase psychological capital in the nursing organization as well. The result that authentic leadership had a direct effect on enhancing leader-member exchange is the same result as the study [18] on corporate employees, supporting the argument of Henderson et al. [5]. These results suggest that nurses' perception of the leader's authentic leadership positively affects the leader-member exchange. Psychological capital and leadermember exchange had direct effects on increasing work meaning. Authentic leadership and organizational culture had indirect effects on increasing work meaning through mediators, 
leader-member exchange and psychological capital, respectively. Particularly, in order to enhance work meaning, psychological capital and leader-member exchange were very important mediators. The result that psychological capital and leader-member exchange had direct effects on work meaning was found to be consistent with the results of a study [10] on Chinese corporate employees, a study [19] on U.S. corporate employees and a study [14] on U.S. nurses. Psychological capital and work meaning had direct effects on enhancing work engagement. Organizational culture and psychological capital had indirect effects on enhancing work engagement through mediators, psychological capital and leader-member exchange, respectively. Particularly, it was confirmed that psychological capital and work meaning are very important mediators to enhance work engagement. This result supports Steger's argument [15], and it is considered that positive psychological factors and work meaning work as important factors to enhance work engagement. Therefore, the psychological factors covered in this study will be of practical help for education, counseling, and various programs to improve the job attitudes of nurses.

\section{Conflict of Interest}

No competing financial interests exist.

\section{References}

1. Kim K. Human resource management system for nurses: challenges and research directions. Korean J Health Serv Manag 2012; 6: 247-258.

2. Wong $\mathrm{C}$, Laschinger $\mathrm{H}$. Authentic leadership, performance, and job satisfaction: the mediating role of empowerment. J Adv Nurs 2013; 69: 947-959.

3. Avey J, Luthans F, Youssef C. The additive value of positive psychological capital in predicting work attitudes and behaviors. J Manag 2010; 36: 430-452.

4. Newman A, Ucbasaran D, Zhu F, Hirst G. Psychological capital: a review and synthesis. J Organiz Behav 2014; 35 : 120-138.

5. Henderson D, Liden R, Glibkowski B, Chaudhry A. LMX differentiation: A multilevel review and examination of its antecedents and outcomes. Leadership Quart 2009; 20: 517-534.

6. Giallonardo L, Wong C, Iwasiw C. Authentic leadership of preceptors: predictor of new graduate nurses work engagement and job satisfaction. J Nurs Manag 2010; 18: 993-1003.

7. Walumbwa F, Avolio B, Gardner W, Wernsing T, Peterson S. Authentic leadership: development and validation of a theory-based measure. J Manag 2008; 34: 89-126.
8. Walumbwa F, Luthans F, Avey J, Oke A. Retracted: Authentically leading groups: The mediating role of collective psychological capital and trust. J Organiz Behav 2011; 32: 4-24.

9. Rego A, Sousa F, Marques C, Cunha M. Authentic leadership promoting employees psychological capital and creativity. J Business Res 2012; 65: 429-437.

10. Luthans F, Avolio B, Walumbwa F, Li W. The psychological capital of Chinese workers: Exploring the relationship with performance. Manag Organiz Rev 2005; 1: 249-271.

11. Walumbwa F, Avolio B, Gardner W, Wernsing T, Peterson S. Authentic leadership: development and validation of a theory-based measure. J Manag 2008; 34: 89-126.

12. Quinn R, McGrath $M$. The transformation of organizational cultures: a competing value perspective. Organiz Cult 1985; 315-334.

13. Liden R, Maslyn J. Multidimensionafity of leadermember exchange: an empirical assessment through scale development. J Manag 1998; 24: 43-72.

14. Luthans F, Avolio B, Avey, J, Norman S. Positive psychological capital: Measurement and relationship with performance and satisfaction. Personnel Psychol 2007; 60: 541-572.

15. Steger M, Dik B, Duffy R. Measuring meaningful work: the work and meaning inventory (WAMI). J Career Assess 2012; 20: 322-337.

16. Bruin G, Henn C. Dimensionality of the 9-item utrecht work engagement scale(UWES-9). Psychol Rep 2013; 112: 788-799.

17. McMurray A, Islam M, Sarros J, Pirola-Merlo A. The impact of leadership on workgroup climate and performance in a non-profit organization. Leader Organiz Develop J 2012; 33; 522-549.

18. Wong C, Cummings G. Authentic leadership: a new theory for nursing or back to basics? J Health Organiz Manage 2009; 23: 522-538.

19. Han $G$, Jekel M. The mediating role of job satisfaction between leadermember exchange and turnover intentions. J Nurs Manag 2011; 19: 41-49.

\section{*Correspondence to}

Hee Young Woo

Department of Nursing

Sahmyook Health University

Republic of Korea 